\title{
Canine and Human Leishmaniasis: Disease Progression to Brazilian Urbanized Areas
}

\section{Danilo C Miguel* and Danilo C Guarnier, DVM}

Laboratory of Leishmania Infection Biology Studies (LEBIL), Biology Institute, State University of Campinas - UNICAMP, Brazil

*Corresponding author: Danilo Ciccone Miguel, BSc, PhD, Graduate Program in Animal Biology, Laboratory of Leishmania Infection Biology Studies (LEBIL), Biology Institute, State University of Campinas - UNICAMP, 13083-862, Campinas, SP, Brazil, Email: dcmiguel@unicamp.br

\begin{abstract}
Leishmaniasis is a complex disease considered one of the most neglected tropical diseases of the world. The importance and role of domestic dogs and wild canids as a source of leishmaniasis infection is well recognized. The present mini-review discusses a series of epidemiological studies that reinforce the need to understand the role of reservoirs and vectors in the expansion of leishmaniasis to Brazilian urbanized areas, as Brazil is a country of continental dimensions and endemic for leishmaniasis. Emphasis isgiven on the diagnostic tools and treatment options that must be recognized as crucial options to prevent expansion of visceral leishmaniasis cases.
\end{abstract}

\section{Keywords}

Canids, Leishmaniasis, Urbanization

\section{Introduction}

\section{Leishmania and leishmaniasis}

Protozoan parasites belonging to the Leishmania genus (subgenera Leishmania, Viannia and Sauro leishmania, Trypanosomatidae, Trypanosomatida, Kinetoplastea, Euglenozoa) alternate their biological cycle between vertebrate and invertebrate hosts [1-4]. In terms of vertebrate hosts, not only humans can be accidentally affected but also dogs and cats. Besides, wild and domestic canids arewell recognized as reservoirs of Leishmania in Brazil. It is estimated that more than 20 species of Leishmania cause leishmaniasis, being transmitted by phlebotomine vectors (Diptera, Psychodidae) $[1,5]$. Although occurring in warm areas, such as Central and South America, Southeast Europe, Asia, Africa and Australia, sandflies can also be found in latitudes greater than $50^{\circ} \mathrm{N}$ in South-West [6].

Basically, the parasite presents two distinct forms, depending on where they are found. When in the digestive tract of the phlebotomine vector, promastigotes present long flagellum and elongated cell body. When parasitizing the mammalian host, it presents round shape and internalized flagellum (amastigote stage) [7].

Leishmaniasis is widely distributed and classified as a prominent neglected disease as it causes up to 40,000 deaths per year, being the Indian sub-continent the region with the highest number of victims followed by Bangladesh, Sudan, South Sudan, Ethiopia, and Brazil. In Brazil, approximately 26,000 cases of cutaneous leishmaniasis (CL) were reported between 2003 and 2007, and approximately 3,500 cases of visceral leishmaniasis (VL) were reported for the same period $[8,9]$. In the New World, $\mathrm{CL}$ is mainly related to Leishmania (Viannia) braziliensis, Leishmania (Leishmania) amazonensis, L. (L.) mexicana, L. (L.) peruviana, L. (V.) panamensis, and $L$. (V.) guyanensis, differing from the Old World distribution, where L. (L.) major, L. (L.) tropica, and L. (L.) aethiopica are routinely identified mainly in the Mediterranean, Middle East and South Asia. L. (L.) donovani is the etiological agent of VL in the Old World while $L$. (L.) infantum causes VL in the New World and Old World [10-12]. VL, in its chronic and systemic form, is characterized by long-term fever, anemia, hepatosplenomegaly and hemorrhages. 


\section{The urbanization of leishmaniasis: Decades of concern}

The increase in the number of leishmaniasis cases is a growing problem of public health in Brazil and in other areas of the American continent. Of particular concern are the statistics that point to its reemergence and expansion of transmission areas, corroborating the recent urbanization of leishmaniasis, which until the mid-1980s affected mainly children in rural regions of Northeast Brazil [13]. In addition, a significant factor to be considered is the incidence of VL associated with immunosuppression, such as in patients with acquired immunodeficiency syndrome and transplanted patients [14-16]. Studies performed in Brazil reported an increase in the incidence of Leishmania/HIV co-infection in the Northeast and Central West regions, with VL being the first opportunistic infection in $60 \%$ of HIV-positive patients in the state of Mato Grosso doSul [17]. The therapeutic approach in this case is extremely complex, since relapse rates after treatment can reach up to $100 \%$ of cases in the absence of effective antiretroviral therapy [18].

Jerônimo and collaborators [19] identified an urban distribution pattern of VL in Natal, capital of Rio Grande do Norte state, with increased case numbers of patients infected by L. (L.) infantum in the early 1990s. In that case, the mortality rate was $\sim 10 \%$ [19]. Outbreaks of VL in other urbanized areas of the Southeast and Central-West regions of the country have been reported. One of the most known examples has been described in the metropolitan area of Belo Horizonte, capital of the State of Minas Gerais, where it was observed the rapid dispersion of $\mathrm{VL}$ among the municipalities in the last 20 years. Between 1994 and 2005, approximately 750 cases were diagnosed and, despite some government surveillance measures for disease control, the number of cases continued to increase in the following years [20].

At the beginning of 2000 , members of 46 families from the municipality of TrêsLagoas (Mato Grosso do Sul State) were diagnosed with asymptomatic VL, accounting for approximately $36 \%$ of infection rate [21]. Barata, et al. [22] conducted a study in municipality of Governador Valadares urban area (Minas Gerais), which revealed VL mortality rates close to $16 \%$ for 86 human cases investigated between 2008 and 2011. Interestingly, the prevalence of $\mathrm{VL}$ in dogs in the same region ranged from 13.6 and $53.4 \%$ [23]. In fact, dogs are implicated as the main domestic reservoirs involved in the transmission of $L$. (L.) infantum [23]. Oliveira, et al. aimed to clarify the role of cats as reservoirs of leishmaniasis, asit is not fully understood in the epidemiological context of leishmaniasis [24]. In a review paper focused on the challenges related to control VL in Brazil, Oliveira, et al. [20] reported that VL outbreaks occur subsequently to the presence of infected dogs, such as the example of cases recorded in Araçatuba, an endemic area located in the Northwest of the state of São Paulo [25].
Lutzomyia longipalpis females are the vectors responsible for the transmission of $L$. (L.) infantum in Brazil and its first capture record in Araçatuba dated 1997 [26]. Lu. longipalpis is highly adapted to the peri-urban and urban environment, thriving in peridomiciliary areas $[19,27]$. There are numerous studies in the literature describing species and feeding habits of these insects increasingly adapted to the human dwellings and their surroundings, which has allowed the closest contact of this vector with humans and their domestic animals, especially dogs, a fact that emphasizes this relevant link in the VL epidemiological chain $[28,29]$.

\section{Canids and leishmaniasis}

Dogs (Canis familiaris) are the most important urban reservoirs known for VL [30] and also present great susceptibility to $L$. (L.) infantum. They are hosts that show a wide range of clinical signs, such as dermatitis, alopecia, hyperkeratosis, lymphadenomegaly, ophthalmological diseases, splenomegaly, hepatomegaly, fever and onychogryphosis [31]. Biochemical tests alterations, such as uremia and hyper globulinemia [32] can be detected. It is important to highlight that the increase in parasitic load in tissues and organs (lymph nodes, bone marrow and spleen) is of great importance in these findings $[33,34]$. In addition to the domestic dog, different wild canids are important reservoirs of this parasite $[35,36]$. Abreu, et al. reported 6 cases of autochthonous canine leishmaniasis in the city of Pedregulho (São Paulo), an area considered non-endemic and free of sandflies; raising the assumption that there is a transit of the parasite independently of humans and domestic dogs in that region [37].

The difficulties of an accurate diagnosis facilitate this transit of reservoirs when it comes to domestic dogs. In 2017, Albuquerque, et al. showed that polymerase chain reaction (PCR) is a molecular tool that has broadened horizons regarding the detection of Leishmania spp. in different tissue samples and different species, also allowing the identification of strains and genotypes of the parasites. Indeed, there areseveral protocols that are sensitive and specific, depending on different factors, such as DNA extraction method, primer sequences, reagents and reaction conditions [38]. In terms of the investigation of wild canids infections, research groups in several countries have applied different techniques. In Croatia, for example, the infection of a gray wolf (Canis lupus) by L. (L.) infantum was confirmed by the isolation of parasite DNA from typical lesions of canine leishmaniasis [39]. Also, it has been shown that out of 67 red foxes (Lupis lupis) in Spain, 74\% tested positive for the presence of $L$. (L.) infantum [40] and in the Iberian peninsula, serological surveys of Canis lupus populations kept in captivity showed that these animals produced antibodies against the parasite, even though in low titres, in addition to the presence of Leishmania DNA [41]. Interestingly, Mol, et al. confirmed the trans- 
mission capacity of $L$. (L.) infantum from maned wolves (Chrysocyon brachyurus) and vinegar dogs (Speothos venaticus) infected without symptoms to invertebrate hosts, probably sustaining the natural parasitic cycle [42]. In South America, especially in Brazil, the presence of $L$. (L.) infantum has been described in marsupials and rodents [43] and canids with a large territorial distribution, such as the crab-eating fox (Cerdocyon thous), hoary fox (Lycalopex vetulus), Chrysocyon brachyurus and Speothos venaticus $[44,45]$. Although these animals are not originally synanthropic, a fact that would place them as secondary reservoirs in the zoonotic VL transmission chain [23], it is possible that the role of these wild canids as potential reservoirs for Leishmania is still enlightened. This fact can be explained by the increasing interaction between humans and forest environments - both by expansion of urban and periurban areas with the population growth, as well as by the increase of ecotourism activities in forest areas - leading to the geographical overlap between wild species and humans (that in many cases, willbe accompanied by their pets).

In 2015, Casanova and colleagues [46] verified that cases of human leishmaniasis in the State of São Paulo occurred after the occurrence of canine leishmaniasis cases. An advance of the disease in the West-East direction of the state was also observed. In this sense, canine cases should serve as sentinels for human cases, preferably well monitored and diagnosed. Savani, et al. reported a case of $V L$ in a dog of a family resident in a gated community in the region of Sousas/Joaquim Egídio districts (metropolitan region of the municipality of Campinas, São Paulo), located around $100 \mathrm{~km}$ from the State capital [47]. DNA obtained from liver and spleen samples implicated $L$. (L.) infantum as the etiological agent in that case.

Moreover, one study compiled epidemiological surveillance data in the same region carried out in 2009 by the Department of Health Surveillance of the Health Department of Campinas. At that time, blood samples from 198 dogs were examined and 4 cases of canine VL confirmed, indicating a prevalence of $2 \%$ of dogs infected with $L$. (L.) infantum [48]. Von Zuben and others carried out further entomological research and found Lu. whitmani (69.5\%) and Lu. longipalpis $(22.5 \%)$ as the predominant sandfly species [48]. Concerning the research of wild mammals that could be implicated in VL transmission, parasite DNA was not detected in any of the captured mammals, including rodent (Nectomys squamipes), primate (Callithrix penicillata) and marsupials (Didelphis albiventris and Gracilinanus agilis). The studies mentioned above that reported Leishmania-infected domestic dogs and the occurrence of competent vectors in the municipality of Campinas were crucial to add the region to the list of municipalities with established canine VL transmission in the state of São Paulo in 2010 [49].
Although the cases diagnosed were related only to dogs, one human CL outbreak has been documented in 1993 and 1994 in the districts of Sousas and Joaquim Egídio involving 25 cases of inhabitants of rural, peri-urban and urban areas. The authors described the mobility pattern of those cases, suggesting a rural-urban flow [50]. Unfortunatley, no identification of Leishmania species has been performed. It is worth mentioning that in 2007, the first two cases of canine infection by L. (L.) amazonensis were described in the city of Araçatuba, considered an endemic area of $\mathrm{VL}$ in the state of São Paulo. The species identified in that case is typically associated with cases of $\mathrm{CL}$ in humans and has wild rodents as its main reservoirs [51].

\section{Challenges and perspectives}

Currently, the diagnosis of canine leishmaniasis is routinely performed in laboratories by direct parasitological examination and/or serological methods. More sensitive and specific methods such as molecular diagnostic tools are currently being applied to detect Leishmania infection, both in clinically suspect dogs and in asymptomatic dogs, which can serve as reservoirs as a possible source of infection for phlebotomine vectors. Recent clinical studies in Iran show that the majority of infected dogs do not show clinical signs [52]. The diagnosis of leishmaniasis in dogs can be considered complex for veterinarians due to:

i. The fact that clinical signs are highly variable in intensity and other pathologies may present similar signs, such as erliquiosis [53];

ii. Histopathological analyses are relatively invasive, costly and time-consuming;

iii. The lack of a highly sensitive and specific diagnostic method available on the market [54].

In this context, a symptom-based clinical score has been adopted to support diagnosis in endemic regions, as seen in Italy, where a severity score based on signs of the disease was proposed [33]. Once the clinical signs are identified, laboratory routine includes direct investigation of the parasite using for ex. puncture smear of lymph node, bone marrow or blood, and/or serological evaluation, by rapid immunochromatographic/ELISA tests. The lack of sensitivity should also be highlighted mainly in cases of subclinical carriers [55]. Polymerase chain reaction (PCR) is a sensitive and specific method, since it shows more reliable results even for healthy animals [56]. By using the PCR methodology, it is possible to amplify target sequences in the genome where the ribosomal DNA array (rDNA) allows the typing of Leishmania species [57].

In general, leishmaniasis chemotherapy is very complex not only for dogs, but also for humans [58]. Given the prohibition of treating dogs with the same drugs used to treat humans in Brazil for a long period,a great 
controversy in veterinary medicine has raised. Recommendation of euthanasia of seropositive animals was supported despitelow effectiveness in disease control. Recently, studies on drugs that act against leishmaniasis have evolved and the use of miltefosine (Milteforan ${ }^{\circledR}$ ) has been approved by the Ministry of Agriculture in 2017. The release of the product mentioned has a strong relation with the exclusively zoonotic character of the disease in Brazil; unlike other countries (i.e., India) where the anthroponotic character is observed. The prophylaxis of leishmaniasis is closely related to the interruption of the transmission of the parasite between the links of the epidemiological chain. Until recently, euthanasia of animals with positive serology was recommended as a prophylactic measure, but this measure proved to be ineffective as there were wild reservoirs with close proximity to dogs and humans, for example, wild canids. Strategies for prophylactic performance in sand flies are those that have presented better results. The use of protective screens and collars repellents, as well as insecticides, plays an important role in controlling the transmission of VL. Unfortunately, it is not possible to rely solely on vaccines for prophylaxis, since the animal may show positive serology after immunization. In addition, the replacement of the animal owner associated with the lack of clinical history can lead to later diagnoses and more severe complications to the animals [59-61]. Unlike observed for humans, there are vaccines currently available for veterinarian use only.

Epidemiological surveys regarding the transmission dynamics and characterization of host-vector-parasite populations are key to achieve a better understanding of leishmaniasis in urbanized and non-urbanized areas. Through the combination of research on surveillance practices and modern parasitological studies, it will be possible to advance in the promotion of prophylactic strategies to restrict the progress of such devastating disease for humans and dogs.

\section{Acknowledgements}

The authors thank Pró-Reitoria de Pesquisa (PRP)UNICAMP and Coordenação de Aperfeiçoamento de Pessoal de Nível Superior (CAPES) for financial support to D.C.M. and scholarship to D.C.G., respectively.

\section{References}

1. Lainson R, Shaw J (1987) The leishmaniasis in Biology and Medicine. Acad Press, London, ISBN: 0125521014.

2. Adl SM, Simpson AG, Farmer MA, Andersen RA, Anderson OR, et al. (2005) The new higher level classification of eukaryotes with emphasis on the taxonomy of protists. $J$ Eukaryot Microbiol 52: 399-451.

3. Bates PA (2007) Transmission of Leishmania metacyclic promastigotes by phlebotomine sand flies. Int $\mathrm{J}$ Parasitol 37: 1097-1106.

4. Raymond F, Boisvert S, Roy G, Ritt JF, Légaré D, et al. (2012) Genome sequencing of the lizard parasite
Leishmania tarentolae reveals loss of genes associated to the intracellular stage of human pathogenic species. Nucleic Acids Res 40: 1131-1147.

5. Killick-Kendrick R (1999) The biology and control of phlebotomine sand flies. Clin Dermatol 17: 279-289.

6. https://ecdc.europa.eu/en/disease-vectors/facts/ phlebotomine-sand-flies

7. Sadlova J, Muskova J, Lestinova T, Votypka J, Yeo M, et al. (2017) Leishmania donovani development in Phlebotomus argentipes: Comparison of promastigote- and amastigoteinitiated infections. Parasitology 144: 403-410.

8. WHO Expert Committee on the Control of the Leishmaniases \& World Health Organization (2010) Control of the leishmaniases: Report of a meeting of the WHO Expert Committee on the Control of Leishmaniases, Geneva, 22-26 March 2010.

9. Alvar J, Vélez ID, Bern C, Herrero M, Desjeaux P, et al. (2012) Leishmaniasis worldwide and global estimates of its incidence. PLoS One 7: e35671.

10. Grimaldi G, Schottelius J (2001) Leishmaniases--Their relationship to monoxenous and dixenous trypanosomatids. Med Microbiol Immunol 190: 3-8.

11. Nawaratna SS, Weilgama DJ, Wijekoon CJ, Dissanayake M, Rajapaksha K (2007) Cutaneous leishmaniasis, Sri Lanka. Emerg Infect Dis 13: 1068-1070.

12. Hammami-Ghorbel $\mathrm{H}$, Bem Abda I, Badri T, Chelbi $\mathrm{H}$, Fenniche S, et al. (2015) Mucosal leishmaniasis of the lip: An emerging clinical form in Tunisia. J Eur Acad Dermatol Venereol 29: 1212-1215.

13. Departamento de Vigilância Epidemiológica, Secretaria de Vigilância em Saúde, Ministério da Saúde DVE-SVS (2006) Manual de vigilância e controle da leishmaniose visceral.

14. Machado CM, Martins TC, Colturato I, Leite MS, Simione AJ, et al. (2009) Epidemiology of neglected tropical diseases in transplant recipients. Review of the literature and experience of a Brazilian HSCT center. Rev Inst Med Trop Sao Paulo 51: 309-324.

15. Albuquerque LC, Mendonça IR, Cardoso PN, Baldaçara LR, Borges MR, et al. (2014) HIVIAIDS-related visceral leishmaniasis: A clinical and epidemiological description of visceral leishmaniasis in northern Brazil. Rev Soc Bras Med Trop 47: 38-46.

16. Mlcallef C, Azzopardi CM (2014) Atypical cutaneous leishmaniasis in the immunosuppressed. BMJ Case Rep pii: bcr2014204914.

17. Botelho AC, Natal D (2009) First epidemiological description of visceral leishmaniasis in Campo Grande, State of Mato Grosso do Sul. Rev Soc Bras Med Trop 42: 503-508.

18. Bern C, Maguire JH, Alvar J (2008) Complexities of assessing the disease burden attributable to leishmaniasis. PLoS Negl Trop Dis 2: e313.

19. Jerônimo SM, Oliveira RM, Mackay S, Costa RM, Sweet J, et al. (1994) An urban outbreak of visceral leishmaniasis in Natal, Brazil. Trans R Soc Trop Med Hyg 88: 386-388.

20. Oliveira CD, Morais MH, Machado-Coelho GL (2008) Visceral leishmaniasis in large Brazilian cities: Challenges for control. Cad Saude Pública 24: 2953-2958.

21. Oliveira AL, Paniago AM, Sanches MA, Dorval ME, Oshiro ET, et al. (2008) Asymptomatic infection in family contacts of patients with human visceral leishmaniasis in Três Lagoas, Mato Grosso do Sul State, Brazil. Cad Saude 
Publica 24: 2827-2833.

22. Barata RA, Peixoto JC, Tanure A, Gomes ME, Apolinário $E C$, et al. (2013) Epidemiology of visceral leishmaniasis in a reemerging focus of intense transmission in Minas Gerais State, Brazil. Biomed Res Int 2013: 405083

23. Dantas-Torres F, Brandão-Filho SP (2006) Visceral leishmaniasis in Brazil: Revisiting paradigms of epidemiology and control. Rev Inst Med Trop Sao Paulo 48: 151-156.

24. Oliveira TM, Pereira VF, Benvenga GU, Martin MF, Benassi JC, et al. (2015) Conjunctival swab PCR to detect Leishmania spp. in cats. Rev Bras Parasitol Vet 24: 220222.

25. Andrade AM, Queiroz LH, Perri SH, Nunes CM (2008) Estudo descritivo da estrutura populacional canina da área urbana de Araçatuba, São Paulo, Brasil, no período de 1994 a 2004. Cad Saúde Pública 24: 927-932.

26. Lutz A, Neiva A (1912) Contribuição para o conhecimento das espécies do gênero Phlebotomus existentes no Brasil. Mem Inst Oswaldo Cruz 4: 84-95.

27. Da Costa AIP, Casanova C, Rodas LAC, Galati EAB (1997) Atualização da distribuição geográfica e primeiro encontro de Lutzomyia longipalpis em área urbana no Estado de São Paulo, Brasil: Notas e Informações. Rev Saúde Pública 31: 632-633.

28. Afonso MM, Duarte R, Miranda JC, Caranha L, Rangel E (2012) Studies on the Feeding Habits of Lutzomyia (Lutzomyia) longipalpis (Lutz \& Neiva, 1912) (Diptera: Psychodidae: Phlebotominae) Populations from Endemic Areas of American Visceral Leishmaniasis in Northeastern Brazil. J Trop Med 2012: 858657.

29. Casanova C, Andrighetti MT, Sampaio SM, Marcoris ML, Colla-Jacques FE, et al. (2013) Larval breeding sites of Lutzomyia longipalpis (Diptera: Psychodidae) in visceral leishmaniasis endemic urban areas in Southeastern Brazil. PLoS Negl Trop Dis 7: e2443.

30. Dantas-Torres $F$ (2007) The role of dogs as reservoirs of Leishmania parasites, with emphasis on Leishmania (Leishmania) infantum and Leishmania (Viannia) braziliensis. Vet Parasitol 149: 139-146.

31. Baneth G, Aroch I (2008) Canine leishmaniasis: A diagnostic and clinical challenge. Vet J 175: 14-15.

32. Freitas JC, Nunes- Pinheiro DC, Lopes Neto BE, Santos GJ, Abreu CR, et al. (2012) Clinical and laboratory alterations in dogs naturally infected by Leishmania chagasi. Rev Soc Bras Med Trop 45: 24-29.

33. Manna L, Reale S, Vitale F, Gravino AE (2009) Evidence for a relationship between Leishmania load and clinical manifestations. Res Vet Sci 87: 76-78.

34. Reis AB, Teixeira-Carvalho A, Giunchetti RC, Guerra LL, Carvalho MG, et al. (2006) Phenotypic features of circulating leucocytes as immunological markers for clinical status and bone marrow parasite density in dogs naturally infected by Leishmania chagasi. Clin Exp Immunol 146: 303-311.

35. Ashford RW (1996) Leishmaniasis reservoirs and their significance in control. Clin Dermatol 14: 523-532.

36. Maia-Elkhoury AN, Alves WA, Sousa-Gomes ML, Sena JM, Luna EA (2008) Visceral leishmaniasis in Brazil: Trends and challenges. Cad Saude Publica 24: 2941-2947.

37. de Abreu CR, Parpinelli AC, de Lima RR, Dias LG, Pereira LF, et al. (2015) Description of six autochthonous cases of canine visceral leishmaniasis diagnosed in Pedregulho
(São Paulo, Brazil). Rev Bras Parasitol Vet 24: 216-219.

38. Albuquerque A, Campino L, Cardoso L, Cortes S (2017) Evaluation of four molecular methods to detect Leishmania infection in dogs. Parasit Vectors 10: 57.

39. Beck A, Beck R, Kusak J, Gudan A, Martinovic F, et al. (2008) A case of visceral leishmaniosis in a gray wolf (Canis lupus) from Croatia. J Wildl Dis 44: 451-456.

40. Criado-Fornelio A, Gutierrez-Garcia L, Rodriguez-Caabeiro F, Reus-Garcia E, Roldan-Soriano MA, et al. (2000) A parasitological survey of wild red foxes (Vulpes vulpes) from the province of Guadalajara, Spain. Vet Parasitol 92: 245-251.

41. Sastre N, Francino O, Ramírez O, Ensenat C, Sanchez A, et al. (2008) Detection of Leishmania infantum in captive wolves from Southwestern Europe. Vet Parasitol 158: 117120.

42. Mol JP, Soave SA, Turchetti AP, Pinheiro GR, Pessanha AT, et al. (2015) Transmissibility of Leishmania infantum from maned wolves (Chrysocyon brachyurus) and bush dogs (Speothos venaticus) to Lutzomyia longipalpis. Vet Parasitol 212: 86-91.

43. Quinnell RJ, Courtenay O (2009) Transmission, reservoir hosts and control of zoonotic visceral leishmaniasis. Parasitology 136: 1915-1934.

44. Silveira FT, Lainson R, Shaw JJ, Póvoa MM (1982) Leishmaniasis in Brazil: XVIII. Further evidence incriminating the fox Cerdocyon thous $(L)$ as a reservoir of Amazonian visceral leishmaniasis. Trans R Soc Trop Med Hyg 76: 830-832.

45. Luppi MM, Malta MC, Silva TM, Silva FL, Motta RO, et al. (2008) Visceral leishmaniasis in captive wild canids in Brazil. Vet Parasitol 155: 146-151.

46. Casanova C, Colla-Jacques FE, Hamilton JG, Brazil RP, Shaw JJ (2015) Distribution of Lutzomyia longipalpis chemotype populations in São Paulo State, Brazil. PLoS Negl Trop Dis 9: e0003620.

47. Savani ES, Presotto D, Roberto T, Camargo MC, D'auria $\mathrm{SR}$, et al. (2011) First occurrence of an autochthonous canine case of Leishmania (Leishmania) infantum chagasi in the municipality of Campinas, State of São Paulo, Brazil. Rev Inst Med Trop Sao Paulo 53: 227-229.

48. Von Zuben AP, Angerami RN, Castagna C, Baldini MB, Donalisio MR, et al. (2014) The first canine visceral leishmaniasis outbreak in Campinas, State of São Paulo Southeastern Brazil. Rev Soc Bras Med Trop 47: 385-388.

49. Secretaria de Estado da Saúde (2010) Comitê de Leishmaniose Visceral Americana. Classificação epidemiológica dos municípios segundo o Programa de Vigilância e Controle da Leishmaniose Visceral Americana no Estado de São Paulo. Bol Epidemiol Paul 7: 21-40.

50. Corte AA, Nozawa MR, Ferreira Md, Pignatti MG, Rangel O, et al. (1996) Eco-epidemiological aspects of American cutaneous leishmaniasis in the Municipality of Campinas, São Paulo, Brazil. Cad Saúde Publica 12: 465-472.

51. Tolezano JE, Uliana SR, Taniguchi HH, Araújo MF, Barbosa JA, et al. (2007) The first records of Leishmania (Leishmania) amazonensis in dogs (Canis familiaris) diagnosed clinically as having canine visceral leishmaniasis from Araçatuba County, SãoPaulo State, Brazil. Vet Parasitol 149: 280-284.

52. Fakhar M, Motazedian MH, Hatam GR, Asgari Q, Kalantari $M$, et al. (2012) Asymptomatic human carriers of Leishmania 
infantum: Possible reservoirs for Mediterranean visceral leishmaniasis in southern Iran. Ann Trop Med Parasitol 102: $577-583$.

53. Tafuri WL, de Oliveira MR, Melo MN, Tafuri WL (2001)Canine visceral leishmaniosis: A remarkable histopathological picture of one case reported from Brazil. Vet Parasitol 96: 203-212.

54. Ferrer LM (1999) Clinical aspects of canine leishmaniasis. In: Proceeding of the International Cnaince Leishmaniasis Forum. Canine Leishmaniasis: an update. Barcelona, Spain, Hoeschst Roussel, Wiesbaden, Vet 6-10.

55. Castellanos-Gonzalez A, Saldarriaga OA, Tartaglino L, Gacek R, Temple E, et al. (2015) A novel molecular test to diagnose canine visceral leishmaniasis at the point of care. Am J Trop Med Hyg 93: 970-975.

56. Zhao GH, Yin K, Zhong WX, Xiao T, Wei QK, et al. (2016) Epidemiological investigation of asymptomatic dogs with Leishmania infection in Southwestern China where visceral leishmaniasis is intractable. Korean J Parasitol 54: 797-801.
57. Van der Auwera G, Dujardin JC (2015) Species typing in dermal leishmaniasis. Clin Microbiol Rev 28: 265-294.

58. Alcântara LM, Ferreira TCS, Gadelha FR, Miguel DC (2018) Challenges in drug discovery targeting TriTryp diseases with an emphasis on leishmaniasis. Int J Parasitol Drugs Drug Resist 8: 430-439.

59. Rowland T, Davidson SA, Kobylinski K, Menses C, Rowton E (2015) Efficacy of permethrin treated bed nets against Leishmania major infected sand flies. US Army Med Dep J 1: 10-15.

60. Duarte MC, Lage DP, Martins VT, Chávez-Fumagalli MA, Roatt BM, et al. (2016) Recent updates and perspectives on approaches for the development of vaccines against visceral leishmaniasis. Rev Soc Bras Med Trop 49: 398-407.

61. Karakuş M, Aykur M, Özbel Y, Töz S, Dağcı H (2016) Molecular detection and genotyping of Acanthamoeba spp. among stray dogs using conjunctival swab sampling. Acta Trop 164: 23-26. 